\title{
Medical management of pneumonia in children aged under 5 years in Alexandria, Egypt: mothers' perspective
}

Noha Fadl, ${ }^{1}$ Ayat Ashour ${ }^{1}$ and Yasmine Muhammed ${ }^{1}$

${ }^{1}$ Family Health Department, High Institute of Public Health, Alexandria University, Alexandria, Egypt (Correspondence to: nohaosama@alexu.edu.eg).

\begin{abstract}
Background: Pneumonia is among the top causes of morbidity and mortality among the under-fives worldwide.

Aims: A cross-sectional study was conducted to assess health-seeking behaviour and first medical management of pneumonia among children aged under 5 years in Alexandria, Egypt from the mothers' perspectives.

Methods: Using a pre-designed questionnaire, we interviewed 507 mothers of pneumonic children aged under 5 years who had been admitted at 4 governmental children's hospitals. The study was conducted during August-November 2017.

Results: We found that $57.2 \%$ of children received home treatment before seeking medical advice. Around $26 \%$ of mothers waited $\geq 2$ days before seeking medical advice; insufficient knowledge about the disease was their main contention (89\%). Factors significantly associated with the delay were: rural residence $(P=0.006)$; low income $(P=0.002)$; home treatment given before seeking medical advice $(P<0.001)$ and previous episodes of pneumonia $(P=0.002)$. Diagnosis of pneumonia had not been made by more than half of the first consulted sources (52.7\%).

Conclusion: There is an urgent need to improve mothers' knowledge and train physicians for appropriate management of pneumonia in children under 5 years.

Keywords: pneumonia, management, under-fives, Egypt

Citation: Fadl N; Ashour A; Muhammed Y. Medical management of pneumonia in children aged under 5 years in Alexandria, Egypt: mothers' perspective. East Mediterr Health J. 2020;26(9):1042-1051. https://doi.org/10.26719/emhj.20.013

Received: 28/10/18; accepted: 12/05/19

Copyright $($ World Health Organization (WHO) 2020. Open Access. Some rights reserved. This work is available under the CC BY-NC-SA 3.0 IGO license (https://creativecommons.org/licenses/by-nc-sa/3.o/igo)
\end{abstract}

\section{Introduction}

Acute respiratory tract infection (ARI) is one of the leading causes of morbidity and mortality among children under 5 years in developing countries. ARI is classified into upper and lower respiratory tract infections (1). Pneumonia, a common and severe lower respiratory tract infection, is recognized as "the forgotten killer of children" (2), killing 1.1-1.4 million children every year and accounting for $17-19 \%$ of all deaths among children under 5 years of age (3). Most of these deaths occur in low- and middle-income countries (4). A recent systematic review indicated 0.22 pneumonia episodes per childyear in low- and middle-income countries, with nearly 1 in 8 cases progressing to severe disease (5).

In the Eastern Mediterranean Region (EMR), reduction of under-five mortality remains an unfinished agenda, with 923000 children under-five year still dying every year in the Region, with pneumonia as the major killer (20\%) (6). The Child Health Epidemiology Reference Group (CHERG) estimated 0.28 episodes per child-year for the EMR. These estimates translate into about 20 million cases of childhood pneumonia each year, with approximately $10 \%$ of cases requiring hospitalization (7). In Egypt, children under 5 years account for nearly $13.4 \%$ of the total population (8), and pneumonia constitutes $19 \%$ of under-five mortality (9). The incidence of pneumonia in Egypt has been estimated at $0.11-0.20$ pneumonia episodes per child-year (7).

Given the frequency of this illness among children under 5 years, the care that must be provided for them imposes a significant burden on parents and health services. In addition, the care provided by the family and the health services is not always the most efficient way to treat this illness (1). Effective antibiotic treatment for pneumonia exists, thus timely recognition of the signs and symptoms by primary care givers and subsequent care-seeking for treatment from appropriate providers can prevent many of these deaths (10). Yet, worldwide, only 3 in 5 children receive the necessary help and care (11).

According to the Egypt Demographic and Health Survey $2014,68 \%$ of children under 5 years with suspected pneumonia sought care from a health provider (8). This implies that many children with potential pneumonia remain untreated (12). Therefore, it is imperative to identify barriers in seeking and receiving the appropriate health care to manage children under 5 years with pneumonia. The aim of the current study was to address mothers'/primary care givers' health-seeking behaviours for children under 5 years with suspected pneumonia and first medical management received from the mothers' perspective. 


\section{Methods}

\section{Study design}

A cross-sectional descriptive study design was used. The study was conducted over a 4-month period, August-November 2017. The study was conducted in the inpatient departments of the following hospitals in Alexandria; El-Shatby Univerity Hospital, Al-Raml Paediatric Hospital, Al-Anfoshy Paediatric Hospital and Fawzy Moaz General Hospital. The sampled hospitals are the main government hospitals providing low-cost health services to the paediatric population from Alexandria and surrounding rural areas.

\section{Study population}

The study population included mothers/primary care givers of all children aged 2-59 months with established diagnosis of pneumonia admitted to the sampled hospitals. Hospital records were checked first to ensure that pneumonia was diagnosed according to WHO diagnostic criteria (i.e. cough and/or difficulty breathing with at least one of the following signs: fast breathing, $\geq 50$ breaths/minute in a child aged 2-11 months, $\geq 40$ breaths/minute in a child aged 12-59 months; or lower chest indrawing) (13).

Exclusion criteria were:

- children with confirmed diagnosis of congenital malformation, tuberculosis, HIV, cardiac or other chronic conditions that might be complicated by pneumonia;

- children with reported cough because of a recent history of aspiration of a liquid or a foreign body;

- mothers or primary care givers refusing to participate in the study.

\section{Sample size}

Based on a prevalence rate of $13.6 \%$ for ARIs among children under 5 years in Egypt (8) and using degree of precision $5 \%$, the minimum required sample size was 362 . The sample size was calculated using EpiInfo, version 7. All sampled hospitals were visited at least twice weekly to cover all cases of pneumonia during the study period. The total sample size was 507 cases fulfilling the predetermined inclusion criteria. No one refused to participate in the present study and only 10 children were not accompanied by their mothers/primary care givers to complete the questionnaire; these were excluded from the study.

\section{Data collection}

Mothers/primary care givers were interviewed by trained data collectors using a pre-designed questionnaire to collect data on sociodemographic characteristics, child's health status, mother's knowledge, health-seeking behaviour and first management received before hospital admission from the mother's perspective. The questionnaire was designed based on data from other similar studies $(10,14,15)$. For content validity, the questionnaire was revised by an expert paediatrician. Then, the questionnaire was translated from English to Arabic by trained bilingual staff. A pilot test $(n=10)$ was conducted on a different group to assure clarity of the questions and check for language errors. Digital scales appropriate for the child age were used for weight measurement.

\section{Definition of measured variables}

- Diagnosis of pneumonia was based on hospital records in which pneumonia was diagnosed according to WHO criteria (13) with or without radiological findings.

- Child's nutritional status was assessed according to WHO child growth standards weight for age. Children below the 5th percentile were categorized as underweight; those plotted above 95th percentile were considered to be overweight (16).

- Exclusive breastfeeding was defined as no other food or drink, not even water, except breast milk (including milk expressed or from a wet nurse) for the first 6 months of life, but allowing the infant to receive oral rehydration salts, drops and syrups (vitamins, minerals and medicines) (17).

- Inappropriate health- seeking behaviours included self-administered treatment, delay in seeking medical advice, seeking advice from inappropriate providers, and noncompliance with the prescribed treatment. Appropriate providers included government and private health providers, but not traditional healers and pharmacists.

- Delay in seeking medical advice was considered if mother/primary care giver of a pneumonic child sought medical help $\geq 2$ days after onset of symptoms.

\section{Statistical analysis}

Collected data was reviewed for completeness and accuracy, coded, computed, cleaned and analysed using SPSS, version 21.0. Descriptive statistics (mean and standard deviation for normally distributed data and median for skewed data) were used for quantitative data and frequency for qualitative data. The Chi squared test was used to test for association in qualitative variables while independent $\mathrm{t}$-test was used for quantitative variables. Statistical significance was set at $P<0.05$.

\section{Ethical considerations}

Before recruiting participants for the study, approvals were obtained from the ethics committee of the High Institute of Public Health, the director of El-Shatby University Hospital and the Ministry of Health and Population. After explaining the purpose of the study, informed consent was obtained from every mother/primary care giver in her own right and on behalf of her child. Participation in the study was entirely voluntary. All information was handled with strict confidentiality. 


\section{Results}

\section{Sociodemographic characteristics}

A total of 507 mothers with under-five pneumonic children were interviewed, (Table 1). The mean age of participating mothers was 28.36 [standard deviation (SD) 5.76] years; $82.1 \%$ were urban residents. Regarding parents' education status, $29.4 \%$ of mothers and $32.1 \%$ of fathers were illiterate. The majority of mothers (91.7\%) were housewives. For paternal occupation, 58\% were skilled workers, $20.3 \%$ were employees (office workers and other staff working for any organization) and 3.6\% were unemployed. The household crowding index was $\leq 2$ in $92.5 \%$

Table 1 Sociodemographic characteristics of parents of pneumonic children aged under 5 years $(n=507)$, Alexandria 2017

\begin{tabular}{|c|c|c|}
\hline Characteristic & No. & $\%$ \\
\hline \multicolumn{3}{|l|}{ Residence } \\
\hline Urban & 416 & 82.1 \\
\hline Rural & 91 & 17.9 \\
\hline $\begin{array}{l}\text { Mean (SD) age of mother } \\
\text { (years) }\end{array}$ & $28.36(5.76)$ & \\
\hline$\leq 20$ & 38 & 7.5 \\
\hline $21-35$ & 401 & 79.1 \\
\hline$>35$ & 68 & 13.4 \\
\hline \multicolumn{3}{|l|}{ Mother's education } \\
\hline Illiterate & 149 & 29.4 \\
\hline Primary & 40 & 7.9 \\
\hline Preparatory & 104 & 20.5 \\
\hline Secondary & 171 & 33.7 \\
\hline University & 43 & 8.5 \\
\hline \multicolumn{3}{|l|}{ Father's education } \\
\hline Illiterate & 163 & 32.2 \\
\hline Primary & 28 & 5.5 \\
\hline Preparatory & 64 & 12.6 \\
\hline Secondary & 212 & 41.8 \\
\hline University & 40 & 7.9 \\
\hline \multicolumn{3}{|l|}{ Mother's occupation } \\
\hline Housewife & 465 & 91.7 \\
\hline Working & 42 & 8.3 \\
\hline \multicolumn{3}{|l|}{ Father's occupation } \\
\hline Not working & 18 & 3.6 \\
\hline Employee & 103 & 20.3 \\
\hline Professional & 92 & 18.1 \\
\hline Skilled & 294 & 58.0 \\
\hline \multicolumn{3}{|l|}{ Home ventilation $^{a}$} \\
\hline Bad & 85 & 16.8 \\
\hline Good & 422 & 83.2 \\
\hline \multicolumn{3}{|l|}{ Paternal smoking at home } \\
\hline Yes & 291 & 57.4 \\
\hline No & 216 & 42.6 \\
\hline
\end{tabular}

SD = standard deviation

aSubjective assessment. of respondents. However, $16.8 \%$ of mothers reported having bad ventilation and 57.4\% reported paternal smoking at home.

Two-thirds of the 507 children under 5 years enrolled in the study (66.1\%) were males (Table 2). Mean age was 18.2 (SD 16.8, range 2-59) months.

\section{Child's health status}

We found that $15.4 \%$ of the children were underweight and $6.1 \%$ were overweight. A quarter of children $(25.6 \%)$

Table 2 Health status of pneumonic children under 5 years $(n=507)$, Alexandria 2017

\begin{tabular}{|c|c|c|}
\hline Quality & No. & $\%$ \\
\hline \multicolumn{3}{|l|}{ Sex } \\
\hline Male & 335 & 66.1 \\
\hline Female & 172 & 33.9 \\
\hline \multicolumn{3}{|l|}{ Age (months) } \\
\hline 2 months- less than one year & 254 & 50.1 \\
\hline $12-36$ months & 180 & 35.5 \\
\hline 37-59 months & 73 & 14.4 \\
\hline Mean (SD) (months) & \multicolumn{2}{|c|}{$18.2(16.8)$} \\
\hline \multicolumn{3}{|l|}{ Nutritional status (weight for age) } \\
\hline Normal & 398 & 78.5 \\
\hline Underweight & 78 & 15.4 \\
\hline Overweight & 31 & 6.1 \\
\hline Mean (SD) (kg) & \multicolumn{2}{|c|}{$10.0(4.4)$} \\
\hline \multicolumn{3}{|l|}{ Breastfeeding } \\
\hline Exclusive breastfeeding & 130 & 25.6 \\
\hline Non- exclusive breastfeeding & 269 & 53.1 \\
\hline No breastfeeding at all & 108 & 21.3 \\
\hline \multicolumn{3}{|l|}{ Vaccination status } \\
\hline Fully immunized up to age & 438 & 86.4 \\
\hline Partially immunized & 62 & 12.2 \\
\hline Not immunized & 7 & 1.4 \\
\hline \multicolumn{3}{|l|}{ First time to acquire pneumonia? } \\
\hline Yes & 348 & 68.6 \\
\hline No & 159 & 31.4 \\
\hline \multicolumn{3}{|l|}{ If no, state no. of episodes $(n=159)$} \\
\hline $1-2$ & 93 & 58.5 \\
\hline $3-5$ & 52 & 32.7 \\
\hline$>5$ & 14 & 8.8 \\
\hline \multicolumn{3}{|l|}{ The first symptoms of illness ${ }^{a}$} \\
\hline Fever & 257 & 50.7 \\
\hline Cough & 210 & 41.4 \\
\hline $\begin{array}{l}\text { Fast breathing/difficult } \\
\text { breathing }\end{array}$ & 256 & 50.5 \\
\hline Nasal blockage & 54 & 10.7 \\
\hline Chest retraction/indrawing & 40 & 7.9 \\
\hline Refusal to feed & 75 & 14.8 \\
\hline $\begin{array}{l}\text { Other (cyanosis, wheezes, } \\
\text { irritability, vomiting, diarrhoea) }\end{array}$ & 20 & 4.0 \\
\hline
\end{tabular}


were exclusively breastfed, and the majority (86.4\%) were vaccinated up to their age.

Around one-third of the children in the study had acquired pneumonia previously; $32.7 \%$ of these had experienced 3-5 episodes and $8.8 \%$ had experienced $>5$ episodes (Table 2). About half of the mothers reported fast breathing/difficult breathing and fever as the first symptoms of illness followed by cough (41.1\%) and refusal to feed (14.8\%).

\section{Knowledge and health-seeking behaviour of mothers}

About half of the mothers (49.3\%) had heard of pneumonia before the onset of their children's recent pneumonia (Table 3); in $60.8 \%$ of those who knew about pneumonia, this was because of their previous experience with their child. Pneumonia was perceived as a serious illness by nearly $70 \%$ of mothers. The most commonly recognized symptoms reported by the mothers were fast breathing/ difficult breathing, fever and cough $(46.7 \%, 21.1 \%$ and $20.0 \%$ respectively). Weather changes/cold weather, poor immunity and smoking were thought to be responsible for pneumonia by $24.1 \%, 17.0 \%$ and $10.8 \%$ of the mothers, respectively. Only $12.0 \%$ stated that infectious agents caused pneumonia. On the other hand, about $38 \%$ had no idea about causes.

On reviewing the mothers' health-seeking behaviour, $57.2 \%$ of the children were given home treatment before seeking medical advice. Antipyretics, cough-relieving drugs and herbs were the most frequently given medications (39.6\%, 19.7\% and $13.0 \%$ respectively) (Table 3). Antibiotics were given by only $4.9 \%$ of the mothers. With reference to timing of the first consultation, $26.8 \%$ of mothers waited for $\geq 2$ days before seeking medical advice. Insufficient knowledge about the signs and symptoms of pneumonia/waiting until their child got better $(89.0 \%)$ was the main stated reason for delay, followed by cost of health services/transportation $(17.6 \%)$, unavailability of a nearby health facility $(10.3 \%)$, inappropriate clinic appointments $(7.3 \%)$ and previous negative experiences (6.6\%).

Sociodemographic characteristics, mother's healthseeking behaviours and child's health status were compared with care-seeking timing for pneumonia. Factors that were significantly associated with delay in seeking medical care for suspected pneumonia were: living in a rural area $(P=0.006)$; low income $(P=0.002)$; treatment given at home before seeking medical advice $(P<0.001)$ and repeated episodes of pneumonia $(P=$ o.002) (Table 4).

Government hospitals/general health care units were the first source consulted by $62.7 \%$ of the mothers followed by private hospitals/clinics (35.1\%) (Table 3). Only $2.2 \%$ sought help from inappropriate providers (pharmacists). In terms of mothers' compliance to the first consulted source, the majority of mothers reported high compliance practices, only $5.6 \%$ of were not compliant with the prescribed treatment (Table 5).
Table 3 Knowledge and health-seeking behaviour of mothers of pneumonic children under 5 years $(n=507)$, Alexandria 2017

\begin{tabular}{|c|c|c|}
\hline Knowledge and health-seeking behaviour & No. & $\%$ \\
\hline \multicolumn{3}{|l|}{ Previous knowledge about pneumonia } \\
\hline Yes & 250 & 49.3 \\
\hline No & 257 & 50.7 \\
\hline \multicolumn{3}{|l|}{$\begin{array}{l}\text { If yes, what was their source of knowledge?a } \\
(n=250)\end{array}$} \\
\hline Previous experience & 152 & 60.8 \\
\hline Relatives/neighbourhoods & 89 & 35.6 \\
\hline TV/media & 11 & 4.4 \\
\hline \multicolumn{3}{|l|}{ Perceived seriousness of pneumonia } \\
\hline I don't know & 91 & 18.0 \\
\hline Not dangerous & 70 & 13.8 \\
\hline Dangerous & 346 & 68.2 \\
\hline \multicolumn{3}{|l|}{ Knowledge of pneumonia symptoms ${ }^{a}$} \\
\hline I don't know & 197 & 38.8 \\
\hline Fast breathing/difficult breathing & 237 & 46.7 \\
\hline Fever & 107 & 21.1 \\
\hline Cough/common cold & 101 & 20.0 \\
\hline Other (cyanosis, vomiting) & 15 & 3.0 \\
\hline \multicolumn{3}{|l|}{ Knowledge of possible causes of pneumonia ${ }^{a}$} \\
\hline I don't know & 195 & 38.5 \\
\hline Malnutrition & 14 & 2.8 \\
\hline Air pollution & 42 & 8.3 \\
\hline Smoking & 55 & 10.8 \\
\hline Overcrowding & 24 & 4.7 \\
\hline Poor immunity & 86 & 17.0 \\
\hline Weather changes/cold weather & 122 & 24.1 \\
\hline Infection & 61 & 12.0 \\
\hline Other (ice cream, cold water, neglect, perfumes) & 27 & 5.3 \\
\hline
\end{tabular}

Treatment given at home before seeking medical help ${ }^{a}$

\begin{tabular}{lcc} 
None & 217 & 42.8 \\
Antipyretic & 201 & 39.6 \\
Antibiotic & 25 & 4.9 \\
Herbs & 66 & 13.0 \\
Cough-relief drugs & 100 & 19.7 \\
Other (bronchodilator, antihistaminic) & 37 & 7.3 \\
iming of first consultation & & \\
\hline First day of child illness & 371 & 73.2 \\
$\begin{array}{l}\text { 2-3 days after child illness } \\
\text { 4-5 days after child illness }\end{array}$ & 105 & 20.7 \\
$\begin{array}{l}\text { 6 days or more after child illness } \\
\text { Causes of delay in seeking medical advice } \mathbf{a}(\mathbf{n}=\mathbf{1 3 6})\end{array}$ & 10 & 4.1 \\
$\begin{array}{l}\text { Insufficient knowledge of signs and symptoms } \\
\text { of pneumonia/waiting until child got better }\end{array}$ & 121 & 89.0 \\
$\begin{array}{l}\text { Cost of health services/transportation } \\
\text { Unavailability of a nearby health facility }\end{array}$ & 24 & 17.6 \\
$\begin{array}{l}\text { Clinic appointments are not appropriate } \\
\text { Previous negative experience }\end{array}$ & 14 & 10.3 \\
\hline
\end{tabular}


Table 3 Knowledge and health-seeking behaviour of mothers of pneumonic children under 5 years $(n=507)$, Alexandria 2017 (continued)

\begin{tabular}{lcc|}
\hline Knowledge and health-seeking behaviour & No. & $\%$ \\
\hline Social norms & 2 & 1.5 \\
Others & 6 & 4.4 \\
Source of first consultation & & \\
$\quad$ Government hospital/general health care unit & 318 & 62.7 \\
Private hospital/private clinic & 178 & 35.1 \\
Pharmacy & 11 & 2.2 \\
\hline
\end{tabular}

${ }^{a}$ Multiple response variable.

\section{First medical management of pneumonia from mothers' perspective}

Diagnosis of pneumonia had not been made by more than half of the first consulted sources (52.7\%). Around $60 \%$ of the first consulted sources did not request inves- tigation (Table 5). Chest X-ray was the most common request $(37.1 \%)$ followed by blood tests $(17.5 \%)$.

In terms of treatment prescribed by the first consulted source, two-thirds of the children $(63.7 \%)$ received home treatment: antipyretics, antibiotics and cough-relieving drugs were the most commonly prescribed treatments (78.0\%, 70.0\% and 53.9\% respectively) (Table 5). About one-quarter of the children (23.5\%) were admitted directly to the hospitals in our sample and received hospital treatment; for $11 \%$ of the sample, the first consulted source referred them to a specialized hospital without prescribing treatment. Only $1.8 \%$ did not receive any treatment at all. The majority of mothers reported high compliance practices: only $5.6 \%$ did not comply with the prescribed treatment.

\section{Discussion}

This study highlighted mothers' perceived barriers in seeking and receiving the proper management of their pneumonic children. We found that nearly one-third of

Table 4 Factors associated with mother's health care-seeking timing, Alexandria 2017

\begin{tabular}{|c|c|c|c|c|c|}
\hline \multirow[t]{2}{*}{ Independent variable } & \multicolumn{2}{|c|}{$\begin{array}{l}\text { Seeking medical advice after } \\
\text { first day of illness }(n=371)\end{array}$} & \multicolumn{2}{|c|}{$\begin{array}{l}\text { Delay in seeking medical } \\
\text { advice }(n=136)\end{array}$} & \multirow[t]{2}{*}{ P-value } \\
\hline & \multicolumn{2}{|c|}{ Mean (SD) } & \multicolumn{2}{|c|}{ Mean (SD) } & \\
\hline Age of mother (years) & \multicolumn{2}{|c|}{$28.44(5.97)$} & \multicolumn{2}{|c|}{$28.21(5.48)$} & 0.682 \\
\hline Age of child (months) & \multicolumn{2}{|c|}{$18.93(17.32)$} & \multicolumn{2}{|c|}{$16.34(15.24)$} & 0.124 \\
\hline \multirow[t]{2}{*}{ Child order } & \multicolumn{2}{|c|}{$1.94(0.73)$} & \multicolumn{2}{|c|}{$2.01(0.71)$} & 0.303 \\
\hline & No. & $\%$ & No. & $\%$ & \\
\hline Sex of child & & & & & 0.277 \\
\hline Male & 240 & 71.6 & 95 & 28.4 & \\
\hline Female & 131 & 76.2 & 41 & 23.8 & \\
\hline Place of residence & & & & & 0.006 \\
\hline Urban & 315 & 75.7 & 101 & 24.3 & \\
\hline Rural & 56 & 61.5 & 35 & 38.5 & \\
\hline Income & & & & & 0.002 \\
\hline Not enough \& borrow & 84 & 64.6 & 46 & 35.4 & \\
\hline Not enough & 57 & 67.8 & 27 & 32.2 & \\
\hline Enough only & 218 & 79.0 & 58 & 21.0 & \\
\hline Enough and saving & 12 & 70.5 & 5 & 29.5 & \\
\hline Mother's education & & & & & 0.358 \\
\hline Illiterate & 112 & 75.2 & 37 & 24.8 & \\
\hline Primary & 24 & 60.0 & 16 & 40.0 & \\
\hline Preparatory & 75 & 72.1 & 29 & 27.9 & \\
\hline Secondary & 129 & 75.4 & 42 & 24.6 & \\
\hline University & 31 & 72.1 & 12 & 27.9 & \\
\hline Treatment given at home before seeking medical help & & & & & $<0.001$ \\
\hline No & 190 & 87.6 & 27 & 12.4 & \\
\hline Yes & 181 & 62.4 & 109 & 37.6 & \\
\hline First time to have pneumonia? & & & & & 0.002 \\
\hline No & 102 & 64.2 & 57 & 35.8 & \\
\hline Yes & 269 & $77 \cdot 3$ & 79 & 22.7 & \\
\hline
\end{tabular}

$S D=$ standard deviation 


\begin{tabular}{|c|c|c|}
\hline Medical management of pneumonia & No. & $\%$ \\
\hline \multicolumn{3}{|l|}{ Diagnosis by the first consulted source } \\
\hline Pneumonia & 240 & $47 \cdot 3$ \\
\hline Common cold & 202 & 39.9 \\
\hline Others (asthma, bronchiolitis) & 65 & 12.8 \\
\hline \multicolumn{3}{|l|}{ Investigation requested by the first consulted source ${ }^{a}$} \\
\hline No & 305 & 60.1 \\
\hline Chest X-ray & 188 & 37.1 \\
\hline Blood test & 89 & 17.5 \\
\hline Other & 4 & 0.8 \\
\hline \multicolumn{3}{|l|}{ Type of medical treatment received at the first consulted source } \\
\hline Home treatment & 323 & 63.7 \\
\hline $\begin{array}{l}\text { Directly admitted to hospital and received hospital treatment (the study setting was their first } \\
\text { consulted source) }\end{array}$ & 119 & 23.5 \\
\hline Referral to specialized hospital without treatment & 56 & 11.0 \\
\hline No prescribed treatment & 9 & 1.8 \\
\hline \multicolumn{3}{|l|}{ Prescribed home treatment $(\mathrm{n}=323)^{a}$} \\
\hline Antipyretics & 252 & 78.0 \\
\hline Antibiotics $^{\mathrm{b}}$ & 226 & 70.0 \\
\hline Cough-relieving drugs & 174 & 53.9 \\
\hline Fluid intake & 11 & 3.4 \\
\hline Others (anti-histaminic, bronchodilator, nebulizer) & 69 & 21.4 \\
\hline \multicolumn{3}{|l|}{ Explanation of prescribed treatment by the first consulted source $(n=323)$} \\
\hline Yes & 302 & 93.5 \\
\hline No & 21 & 6.5 \\
\hline \multicolumn{3}{|l|}{ Mothers' compliance with prescribed treatment $(n=323)$} \\
\hline Yes & 305 & 94.4 \\
\hline No & 18 & 5.6 \\
\hline
\end{tabular}

${ }^{a}$ Multiple response variable.

${ }^{b}$ Median duration of prescribed antibiotics $=3$ days.

mothers had no idea about the symptoms, causes and seriousness of pneumonia. This lack of knowledge and poor perceived seriousness may be related to the high number of mothers without any formal education or any awareness about pneumonia. In accordance with our findings, poor knowledge about pneumonia $(71 \%)$ has been reported in another developing country, Bangladesh (18). A UNICEF/WHO report showed that only 1 in 5 care givers knew the 2 tell-tale or indicative symptoms of pneumonia: fast breathing and difficult breathing (2).

More than half of the mothers were reluctant to seek medical advice and they tended to give treatment at home before seeking medical advice, which agrees with findings that health care in developing countries occurs at home (19). Most of the home treatments were related to symptomatic relief (antipyretics, cough relief drugs, herbs), which can be beneficial are but not sufficient for improving health outcomes in pneumonic children. It may imply poor perceived seriousness of the disease among the mothers.

Unexpectedly, antibiotics were used before seeking medical help by only $5 \%$ of the mothers in our study.
Mothers were aware of antibiotics but expressed limited experience of handling these drugs at home without a prescription from a health provider, especially during this critical young age. This might be related to the large number of mothers with limited income, low education level and poor knowledge. However, home treatment with antibiotics has been reported in a variety of previous studies $(14,20)$.

Reviewing health care-seeking timing, nearly onequarter of the mothers reported a delay in seeking medical care. Previous studies have reported delay in the decision to seek care of 2 or 3 days $(21,22)$. In the present study, the main claim for delay was mothers' insufficient knowledge about signs and symptoms of pneumonia. Similarly, Hill et al. report that, in addition to poor maternal recognition, health beliefs may also act as barriers to care-seeking for childhood illnesses; for example, some illnesses are categorized as "not for hospital", and past experience with similar illnesses can motivate mothers to play a waiting game to see if the illness subsides on its own (23). 
It was further noted that mothers from rural areas or those with low incomes were more likely to postpone visiting health professionals. This may be explained by poorer accessibility to health care facilities (cost of health services/transportation or unavailability of a nearby health facility). Similarly, an Ethiopian study showed that more care givers in urban areas $(75.0 \%)$ sought medical care for children with ARI compared with those in rural areas (34.4\%) (24). Additionally, Noordam et al. stated that there is a strong association between wealth and careseeking in Ethiopia, Tanzania, Nigeria and Burkina Faso (10).

It is not unexpected that mothers giving home treatment were more likely to delay seeking an outside health provider. Our results were similar to the findings of Pajuelo et al. and Källander et al. in Peru and Uganda $(21,25)$. The latter study indicated that giving treatment at home was a risk factor for the delay in seeking medical care for fatal pneumonia (25).

Mothers of children with recurrent episodes of pneumonia tended to defer their health care visits. This might be related to the mothers' poor perception of the seriousness of the disease and/or using previous prescriptions at home. It is worth noting that repeated pneumonia in a child was not uncommon in the present study. Similar findings have been reported in Bangladesh and Peru $(18,21)$; this may be attributed to persistent exposure to environmental risk factors such as exposure to tobacco smoke $(26,27)$, overcrowding $(28)$ or indoor and outdoor pollution $(29,30)$.

In terms of compliance, the vast majority of the mothers (94.4\%) were compliant with the health provider's instructions. This is further strengthened by the finding of Onwunaka et al in a study in Nigeria (31). The reason for the high compliance practices among mothers in our study could be a result of the excellent attention given by health care providers to mothers or the perceived seriousness of the disease.

Reviewing medical management, there was a lack of recognition of pneumonic children by nearly half of the first consulted sources, although most of these were medical providers. In accordance to our finding, previous studies have shown that many developing countries still face significant challenges in the provision of effective health care in the diagnosis and treatment of pneumonia $(21,32)$. The diagnostic challenge of childhood pneumonia lies in the broad range of presenting features. Children can present with pneumonia at different stages of illness and with clinical features that might be difficult to discriminate from other common paediatric conditions (33).
Although chest X-ray is the most commonly used diagnostic tool for childhood pneumonia, nearly twothirds of the first consulted sources did not ask for any investigation. The use of chest $\mathrm{X}$-ray in the clinical context is controversial, with recent guidelines advocating that chest X-ray for the diagnosis of pneumonia in the community setting are warranted. Its use should be confined to children with clinical signs suggesting severe pneumonia who require hospitalization (34).

A recent UNICEF report states that only $39 \%$ of children with suspected pneumonia received antibiotics (35). In contrast, our findings showed that antibiotics were prescribed by nearly three-quarters of first consulted sources, with a median duration of 3 days. However, children were not improved and were referred to the sampled hospitals; questioning the appropriateness of the prescribed antibiotics and their efficacy.

The findings from the current study should be interpreted in light of the following limitations. The study was hospital-based, so we recruited only individuals who had actually made it to the hospital. Also, the retrospective nature of the questionnaire might have resulted in some reporting bias. Finally, the current study was susceptible to social desirability bias.

Despite these limitations, the present study indicated that the main barriers that hinder proper management of pneumonia among children under 5 years in Egypt are delay in health care-seeking, mainly due to mothers' poor knowledge about pneumonia, combined with delay in reaching the proper diagnosis and prescribing appropriate treatment by the health provider. Community-based health education campaigns complementing clinicbased Integrated Management of Childhood Illness programmes can reinforce mothers' abilities to recognize childhood pneumonia, raise awareness regarding causes, predisposing factors and preventive measures of the disease, appreciate seriousness of the disease and subsequently enhance mothers' health-seeking behaviour. Media also could play an important role in raising mothers' awareness about the disease. We believe it is imperative to embark on continuous training for health providers to improve their capability to accurately identify, diagnose and treat fast breathing and chest indrawing pneumonia with proper antibiotics and thus avoid antibiotic misuse.

Funding: The underlying research has received financial support from WHO Regional Office for the Eastern Mediterranean under the EMRPPH grant scheme, project number RPPH 16-105.

Competing interests: None declared. 


\section{Prise en charge de la pneumonie chez les enfants de moins de 5 ans à Alexandrie (Égypte) : le point de vue des mères \\ Résumé}

Contexte : La pneumonie est l'une des causes principales de morbidité et de mortalité chez les moins de 5 ans au niveau mondial.

Objectifs : Une étude transversale a été menée pour examiner le comportement de recours aux soins et la prise en charge initiale de la pneumonie chez les enfants âgés de moins de 5 ans à Alexandrie (Égypte), du point de vue des mères.

Méthodes: Au moyen d'un questionnaire conçu à cet effet, nous avons interrogé 507 mères d'enfants atteints de pneumonie de moins de 5 ans qui avaient été admis dans quatre hôpitaux pédiatriques publics. La présente étude a été réalisée entre août et novembre 2017.

Résultats : D'après nos observations, $57,2 \%$ des enfants avaient reçu un traitement à domicile avant de consulter un médecin. Près de $26 \%$ des mères avaient attendu deux jours ou plus avant de consulter un médecin. Dans la majorité des cas ( $89 \%)$, elles estimaient manquer de connaissances sur la maladie. Les facteurs associés de manière significative à ce retard à la consultation étaient les suivants : vie en milieu rural $(p=0,006)$, faibles revenus $(p=0,002)$, administration d'un traitement à domicile avant la consultation d'un médecin $(p<0,001)$ et épisodes précédents de pneumonie $(p=0,002)$. Le diagnostic de pneumonie n'avait pas été établi par plus de la moitié (52,7\%) des sources initialement consultées.

Conclusion : Afin de prendre en charge la pneumonie chez les enfants âgés de moins de 5 ans de manière satisfaisante, il est urgent d'améliorer les connaissances des mères et de mieux former les médecins.

$$
\text { الأمهاتج الطبي للالتهاب الرئوي في الأطفال الذين تقل أعلارهم عن 0 سنوات في الإسكندرية، مصر : من منظور }
$$

$$
\text { الخلفية: يُعتبر الالتهاب الرئوي من أهم أسباب المراضة والوفيات في الأطفال الذين تقل أعمارهم عن } 5 \text { سنوات على مستوى العالم. }
$$

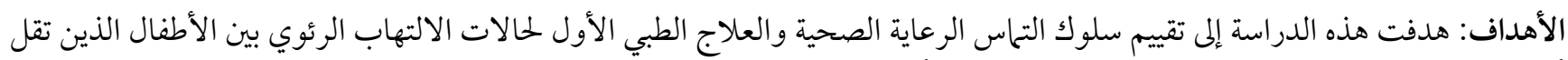

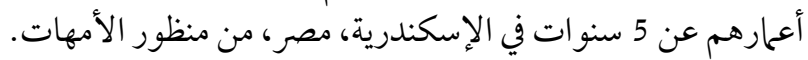

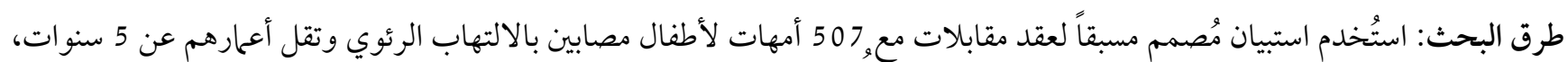

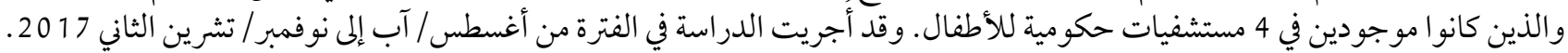

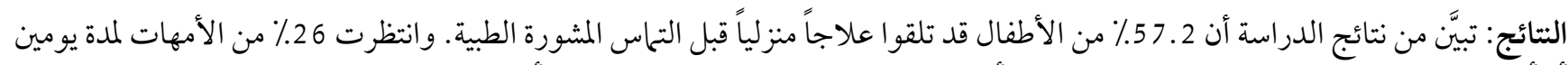

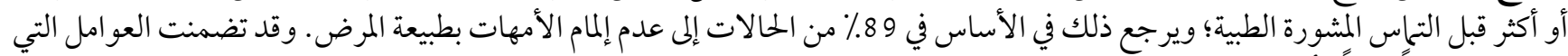

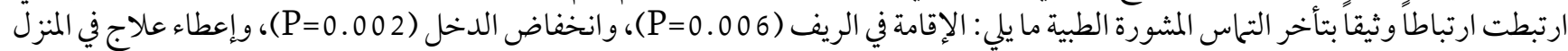
قبل التماس المشورةٍ الطبية (>

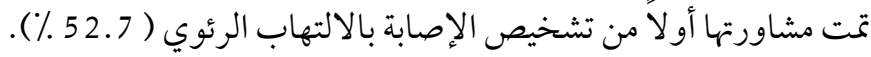

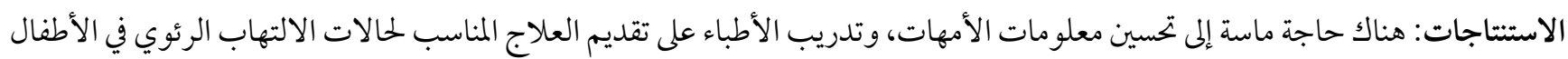
الذين تقل أعمارهم عن 5 سنوات ماتسة

\section{References}

1. Abdel Khalek E, Abdel-Salam D. Acute respiratory tract infections in children under 5 years of age in Upper Egypt. Int J Community Med Public Health. 2016;3(5):1161-6. doi:10.18203/2394-6040.ijcmph20161377

2. Wardlaw TM, Johansson EW, Hodge M. Pneumonia: the forgotten killer of children. New York: UNICEF, World Health Organization; 2006.

3. Bhutta ZA, Das JK, Walker N, Rizvi A, Campbell H, Rudan I, et al. Interventions to address deaths from childhood pneumonia and diarrhoea equitably: what works and at what cost? Lancet. 2013;381(9875):1417-29. doi:10.1016/So140-6736(13)60648-0

4. Nair H, Simões E, Rudan I, Gessner B, Azziz-Baumgartner E, Zhang J, et al. Global and regional burden of hospital admissions for severe acute lower respiratory infections in young children in 2010: a systematic analysis. Lancet. 2013;381:1380-90. doi:10.1016/ So140-6736(12)61901-1 
5. Rudan I, O'Brien KL, Nair H, Liu L, Theodoratou E, Qazi S, et al. Epidemiology and etiology of childhood pneumonia in 2010: estimates of incidence, severe morbidity, mortality, underlying risk factors and causative pathogens for 192 countries. J Glob Health. 2013;3:010401. doi:10.7189/jogh.03.010401

6. Saving the lives of mothers and children: rising to the challenge. Background document for the High Level Meeting on Saving the Lives of Mothers and Children: Accelerating Progress Towards Achieving MDGs 4 and 5 in the Region, Dubai, United Arab Emirates, 29-30 January 2013. Geneva: World Health Organization; 2013.

7. Rudan I, Boschi-Pinto C, Biloglav Z, Mulholland K, Campbell H. Epidemiology and etiology of childhood pneumonia. Bull World Health Org. 2008;86:408-16. PMCID: PMC2647437

8. Egypt Demographic and Health Survey 2014. Cairo, Egypt and Rockville, Maryland, USA: Ministry of Health and Population and ICF International; 2015.

9. Liu L, Johnson HL, Cousens S, Perin J, Scott S, Lawn JE, et al. Global, regional, and national causes of child mortality: an updated systematic analysis for 2010 with time trends since 2000. Lancet. 2012;379(9832):2151-61. doi:10.1016/So140-6736(12)60560-1

10. Noordam A, Carvajal-Velez L, Sharkey A, Young M, Cals J. Care seeking behaviour for children with suspected pneumonia in countries in Sub-Saharan Africa with high pneumonia mortality. PLoS One. 2015;10(2). doi:10.1371/journal.pone.0117919

11. Childhood diseases. New York: UNICEF; 2017 (https://www.unicef.org/health/index_91917.html, accessed 23 February 2020).

12. Mosites EM, Matheson AI, Kern E, Manhart LE, Morris SS, Hawes SE. Careseeking and appropriate treatment for childhood acute respiratory illness: an analysis of Demographic and Health Survey and Multiple Indicators Cluster Survey datasets for high-mortality countries. BMC Public Health. 2014;14(1):1-8. doi:10.1186/1471-2458-14-446.

13. Pocket book of hospital care for children: guidelines for the management of common illnesses with limited resources, 2nd ed. Geneva: World Health Organization; 2013.

14. Ndu IK, Ekwochi U, Osuorah CD, Onah KS, Obuoha E, Odetunde OI, et al. Danger signs of childhood pneumonia: caregiver awareness and care seeking behavior in a developing country. Int J Pediatr. 2015;2015:1-7. doi:10.1155/2015/167261

15. Emery DP, Milne T, Gilchrist CA, Gibbons MJ, Robinson E, Coster GD, et al. The impact of primary care on emergency department presentation and hospital admission with pneumonia: a case-control study of preschool-aged children. NPJ Primary Care Respirat Med. 2015;25:14113. doi:10.1038/npjpcrm.2014.113

16. WHO Multicentre Growth Reference Study Group. WHO child growth standards: length/height-for-age, weightforage, weightfor-length, weight-for-height and body mass index-for-age: methods and development. Geneva: World Health Organization; 2006 .

17. Indicators for assessing infant and young child feeding practices: conclusion of a consensus meeting held 6-8 November 2007 in Washington DC, USA. Geneva: World Health Organization; 2008.

18. Ferdous F, Farzana F D, Ahmed S, Das SK, Abdul Malek M, Das J, et al. Mothers' perception and healthcare seeking behavior of pneumonia children in rural Bangladesh. ISRN Family Med. 2014;2014. doi:10.5402/2014/690315

19. WCountdown to 2015 decade report 2000-2010: taking stock of maternal, newborn and child survival. Geneva: World Health Organization and UNICEF; 2010.

20. Tuhebwe D, Tumushabe E, Leontsini E, Wanyenze RK. Pneumonia among children under five in Uganda: symptom recognition and actions taken by caretakers. African Health Sci. 2014;14(4):993-1000. doi:10.4314/ahs.v14i4.31

21. Pajuelo MJ, Anticona Huaynate C, Correa M, Mayta Malpartida H, Ramal Asayag C, Seminario JR, et al. Delays in seeking and receiving health care services for pneumonia in children under five in the Peruvian Amazon: a mixed-methods study on caregivers' perceptions. BMC Health Serv Res. 2018;18:149. doi:10.1186/s12913-018-2950-Z

22. Onyango D, Kikuvi G, Amukoye E, Omolo J. Risk factors of severe pneumonia among children aged 2-59 months in western Kenya: a case control study. Pan African Med J. 2012;13:45. PMCID:PMC3542783

23. Hill Z KC, Arthur P, Kirkwood B, Adjei E. Recognizing childhood illnesses and their traditional explanations: exploring options for care-seeking interventions in the context of the IMCI strategy in rural Ghana. Trop Med Int Health. 2003;8:668-76. PMID:12828551

24. Assefa T, Belachew T, Tegegn A, Deribew A. Mothers' health careseeking behaviour for childhood illnesses in Derra district, Northshoa Zone, Oromia Regional State, Ethopia. Ethiopian J Health Sci. 2008;18(3):87-94.

25. Källander K, Hildenwall H, Waiswa P, Galiwango E, Peterson S, Pariyo G. Delayed care seeking for fatal pneumonia in children aged under five years in Uganda: a case-series study. Bull World Health Org. 2008;86(5):321-416. doi:10.2471/BLT.07.049353

26. Cheraghi M, Salvi S. Environmental tobacco smoke (ETS) and respiratory health in children. Eur J Pediatr. 2009;168:897-905. doi:10.1007/s00431-009-0967-3

27. Polanska K, Hanke W, Ronchetti R, van den Hazel P, Zuurbier M, Koppe J G, et al. Enviromental tobacco smoke exposure and children's health. Acta Paediatr Suppl. 2006;95(453):86-92. doi:10.1080/08035320600886562

28. Savitha MR, Nandeeshwara SB, Pradeep Kumar MJ, ul-Haque F, Raju CK. Modifiable risk factors for acute lower respiratory tract infections. Indian J Pediatr. 2007;74:477-82. PMID:17526960

29. Searing D A, Rabinovitch N. Environmental pollution and lung effects in children. Curr Opin Pediatr. 2011;23:314-18. doi:10.1097/ MOP.obo13e3283461926. 
30. Vieira SE, Stein RT, Ferraro AA, Pastro LD, Pedro SSC, Lemos M, et al. Urban air pollutants are significant risk factors for asthma and pneumonia in children:the influence of location on the measurement of pollutants. Arch Broncopneumol. 2012;48(11):38995. doi:10.1016/j.arbres.2012.05.005

31. Onwunaka C, Nwimo IO, Ilo CI, Okafor JO. Maternal compliance practices during childhood pneumonia in Imo State, Nigeria. J Health Med Nurs. 2015;15:72-9.

32. Bagonza J, Rutebemberwa E, Eckmanns T, Ekirapa-Kiracho E. What influences availability of medicines for the community management of childhood illnesses in central Uganda? Implications for scaling up the integrated community case management programme. BMC Public Health. 2015;15:1180. doi:10.1186/s12889-015-2525-4.

33. Rodrigues CMC, Groves H. Community-acquired pneumonia in children: the challenges of microbiological diagnosis. J Clin Microbiol. 2018;56(3):e01318-17. doi:10.1128/JCM.01318-17.

34. O'Grady KAF, Torzillo PJ, Frawley K, Chang AB. The radiological diagnosis of pneumonia in children. Pneumonia. 2014;5(1):38-51. doi:10.15172/pneu.2014.5/482

35. Committing to child survival: a promise renewed, progress report. New York: UNICEF; 2015 (http://www.apromiserenewed.org/ wp-content/uploads/2015/o9/APR_2015_8_Sep_15.pdf, accessed 26 September 2018). 